\title{
Long-Term Activity of Thermoplastic Gel Electrolyte in a Photo-Electrochemical Assembly Involving Poly Bithiophene (PBTh) as Photoactive Working Electrode
}

\author{
Kasem K. Kasem \\ School of Sciences, Indiana University Kokomo, Kokomo, USA \\ Email: kkasem@iuk.edu
}

How to cite this paper: Kasem, K.K. (2021) Long-Term Activity of Thermoplastic Gel Electrolyte in a Photo-Electrochemical Assembly Involving Poly Bithiophene (PBTh) as Photoactive Working Electrode. Journal of Materials Science and Chemical Engineering, 9, 1-11.

https://doi.org/10.4236/msce.2021.96001

Received: March 13, 2021

Accepted: June 26, 2021

Published: June 29, 2021

Copyright $\odot 2021$ by author(s) and Scientific Research Publishing Inc. This work is licensed under the Creative Commons Attribution International License (CC BY 4.0).

http://creativecommons.org/licenses/by/4.0/

\begin{abstract}
Evidence for the long period of a sustainable function of a thermoplastic gel electrolyte (TPGE) consists of polyethylene glycol (PEG)/ $\mathrm{I}_{2} / \mathrm{I}^{-}$in propylene carbonate $(\mathrm{PC})$ was recorded. The studied photoactive assembly consists of $\mathrm{PBTH} / \mathrm{FTO} / \mathrm{TPGE} \mathrm{I}_{2} / \mathrm{I}^{-} /$Platinized FTO. The study showed that the assembly regenerates the expected photoelectrochemical (PEC) quantities such as photocurrent, and other dielectric properties with infrequent use through an elapsed period of 18 months. The behavior of PBTh/occluded with CdS was mentored during this period and showed a similar result. PEC studies indicated the presence of $\mathrm{p}-\mathrm{p}$ type hole accumulations interface, evident from the initial sharp rise in photocurrent. The change of open circuit potential $\left(\mathrm{d} V_{o c}\right)$ indicates that the shortest electron lifetime is $100 \mathrm{~ms}$. The behavioral outcome of the assemblies within the period of study refracts stability of the electrode and the long life cycle of the electrolyte.
\end{abstract}

\section{Keywords}

Sustainability, Gel-Polymer, Electrochemistry, Thermoplastic, Photoactivity

\section{Introduction}

The phenomena of corrosion and evaporation represent disadvantages that limit the sustainable use of liquid electrolytes used in dye-sensitized solar cells (DSSC). The use of polymer gel electrolytes is a potential alternative solution to these disadvantages. Several studies were focused on fabrication, working principle, and the up-to-date status of DSSCs and batteries using polymer electrolytes [1] [2] 
[3] [4]. However, solving stability issues came at the expense of efficiency issues. Solid polymer electrolytes where polyether and biopolymer-salt complexes played an important role were investigated [5] [6] [7] [8]. The excellent conductivity, sustainable thermal stability, and ability to form biodegradable film formation abilities, promote their potential to make them suitable electrolyte materials for DSSCs. The use of reactive polymers that possess sol-gel transition or phase separation properties with temperature changes as electrolytes was investigated to follow up with the thermal loss of electrochemical (EC) storage devices such as supercapacitors and lithium-ion batteries [9] [10] [11] [12].

The physical state of the electrolyte, as well as the importance of the redox system used in these electrolytes, are both important. This is because the redox system can affect the electrochemical potential at the counter electrode. This consequently affects the photovoltage outcome of the solar cell. For these reasons, the choice of the redox system in photoelectrochemical (PEC) cells is a very important step towards improving conversion efficiency. Many redox systems were used, but the issues of solubility, light absorption, and stabilities as well as low efficiency [13] [14] were concerns that limited their use. Further, gel-state electrolytes, especially thermoplastic gel electrolytes (TPGE) may have several advantages over liquid state electrolytes such as longer-term stability (life cycles), wide ranges of temperature change tolerance, no loss in the electrolyte contents, and non-flammable electrode reaction products.

$\mathrm{I}^{-} / \mathrm{I}_{3}^{-}$possesses several desirable properties [15] [16] [17], such as good solubility, low absorption of light, a suitable redox potential, fast dye generation, and very slow recombination with some inorganic semiconductors such as $\mathrm{TiO}_{2}$, therefore $\mathrm{I}^{-} / \mathrm{I}_{3}^{-}$attracts attention for use in electrochemical and DSSC devices. A study [18] showed that a balance $\mathrm{I}^{-} / \mathrm{I}_{3}^{-}$is required to generate maximum electrochromic effects. The $\mathrm{I}^{-} / \mathrm{I}_{3}^{-}$was used as redox-active material in the proposed TPGE.

In this study, we explore the sustainability of both the TPGE and the photoactive organic film of poly bithiophene (PBTh) assembled in PEC cells for 18 months. The effect of doping of the photoactive film on the overall cell activity was also explored.

\section{Experimental}

\subsection{Reagents}

The monomer 2,2-bithiophene (BTh), (Alfa Aesar) was used to prepare poly 2,2bithiophene (PBTh). Polyethylene glycol (PEG M-8000) (Sigma/Aldrich) was used for the preparation of the gel electrolyte, Potassium iodide (KI) and Iodine $\mathrm{I}_{2}$ (lab grade, Fisher). Other chemicals used in this study were of analytical grade. Deionized (DI) water was used to prepare aqueous electrolytes.

\subsection{Preparation of Thermoplastic Gel Electrolyte (TPGE)}

Thermoplastic gel electrolyte (TPGE) wAs-prepared following the published pro- 
cedure [19] briefly $0.65 \mathrm{M} \mathrm{KI}$ and $0.065 \mathrm{M} \mathrm{I}_{2}$ (to form $\mathrm{I}^{-} / \mathrm{I}_{3}^{-}$) dissolved in $10 \mathrm{~mL}$ propylene carbonate (PC), and then $8.5 \mathrm{~g}$ of Polyethylene glycol (PEG M-8000) was added to the mixture. The mixture was heated at $100^{\circ} \mathrm{C}$ under continuous stirring for ca. $12 \mathrm{~h}$ in a flask under an inert atmosphere. In a Teflon autoclave, the mixture was heated at $180^{\circ} \mathrm{C}$ for $14 \mathrm{~h}$ for hydrothermal treatment.

\subsection{Instrumentation}

Electro-polymerization was performed in a $20 \mathrm{~cm}^{3}$ three-electrode cell, consisting of a Pt flag as a counter electrode, an $\mathrm{Ag} / \mathrm{AgCl}$ as a reference electrode, and FTO with a surface area of $2.0 \mathrm{~cm}^{2}$ as the working electrode [20]. The generated film thickness was $\approx 1 \mu \mathrm{m}$. Photoelectrochemical studies of the thin solid films were performed using the experimental setup as described in Figure 1. The gel electrolyte was poured on the top of the working electrode, and the counter electrode was pressed on the top of the gel electrolyte to make a uniform electrolyte thickness of $10 \mu \mathrm{m}$. A Solartron 2101A was used for the electrochemical impedance spectroscopy (EIS) studies. A BAS100W electrochemical analyzer (Bioanalytical Co. IN) was used to perform the electrochemical studies. For illumination source, a solar simulator 300-watt xenon lamp with an IR filter (Olympus BX-FL, Newport, NJ) was used. During investigation time (18 months), the assembly shown in Figure 1 was stored in dark at $298 \mathrm{~K}$, where all measurements were performed.

\section{Results and Discussion}

\subsection{Electrochemical Studies on FTO/PBTH/TPGE}

The EC studies on FTO/modified with PBTh were carried out by cycling the potential of FTO modified with each assembly in the thermoplastic $\mathrm{I}^{-} / \mathrm{I}_{3}^{-}$gel electrolyte (TPGE). The studies were performed in dark and under illumination, with a scan rate of $0.10 \mathrm{~V} / \mathrm{s}$, between -1.0 to $1.0 \mathrm{~V}$ vs $\mathrm{Ag} / \mathrm{AgCl}$ unless otherwise stated. The results are displayed in Figure 2 and Figure 3.

Figure 2(A) displays the cyclic voltammetry (CV) of PBTh film, as prepared, in $\mathrm{I}^{-} / \mathrm{I}_{3}^{-}$gel electrolyte in the dark and under illumination, while Figure 2(B)

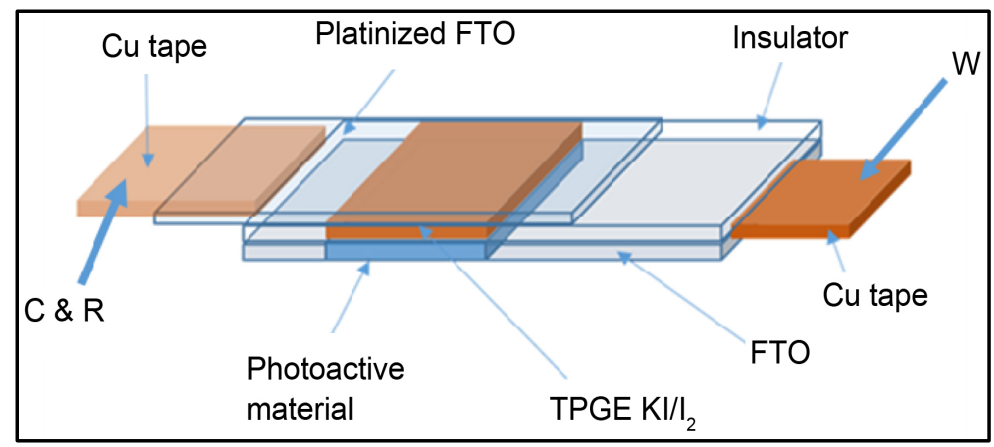

Figure 1. Photoelectrochemical cell-based thermoplastic gel electrolyte (TPGE). $\mathrm{W}=$ Working electrode, $\mathrm{C}=$ Counter electrode, $\mathrm{R}=$ reference electrode. 


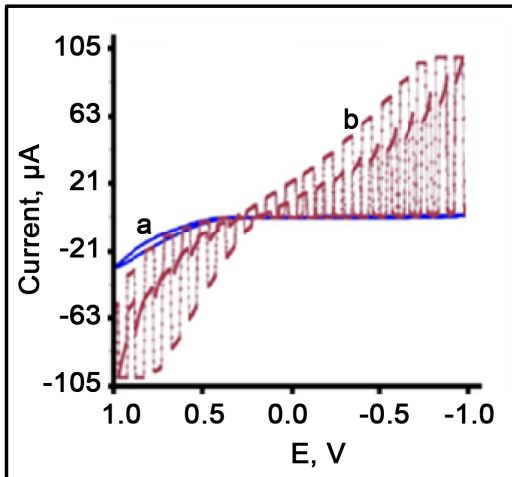

(A)

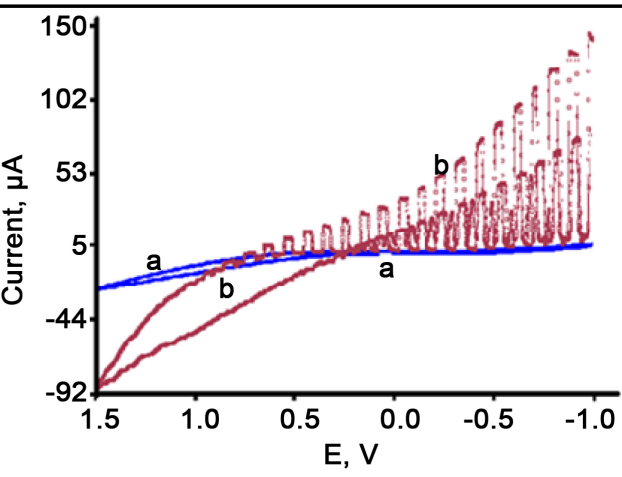

(B)

Figure 2. CV at scan rate $0.1 \mathrm{~V} / \mathrm{s}$ for $\mathrm{PBTh} / \mathrm{I}^{-} / \mathrm{I}_{3}^{-}$gel electrolyte recorded (A) As-prepared, and (B) 18 months later, (a) dark and (b) under illumination.

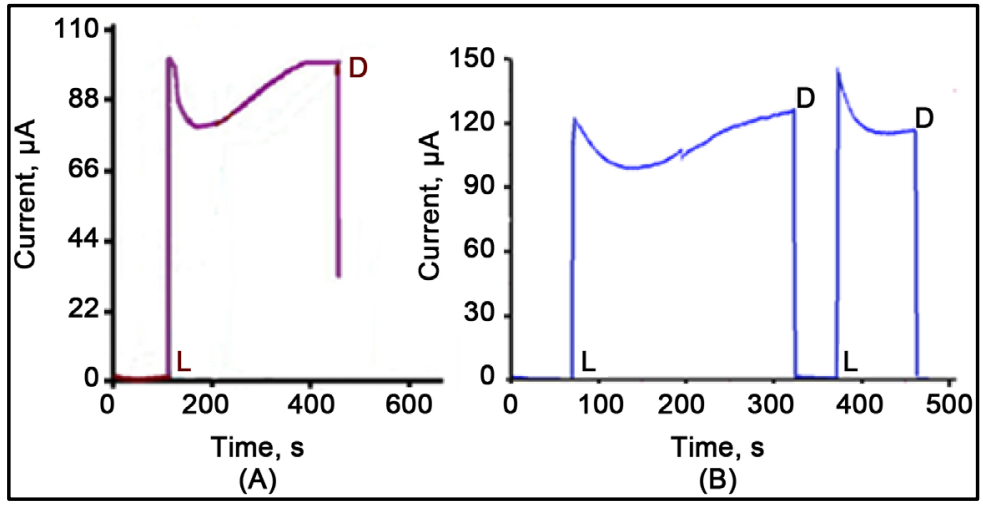

Figure 3. Photocurrent-time at $-1.00 \mathrm{~V}$ plot for $\mathrm{PBTh} / \mathrm{I}^{-} / \mathrm{I}_{3}^{-}$gel electrolyte recorded (A) As-prepared, and (B) 18 months later; D (Dark) and L (illumination).

displays the CV for the same assembly 18 months later. Figure 2(A) and Figure 2(B) indicate that films of PBTh maintained their photoactivity during this period, as evident with the level of generated photocurrent in a potential range between 0.0 and $-1.0 \mathrm{~V}$ vs $\mathrm{Ag} / \mathrm{AgCl}$. The observed greater photocurrent than the dark current in Figure 2(A) and Figure 2(B), indicates that films of PBTh/Gel electrolyte assembly offered great charge separation and small charge recombination. As the photocurrent is a product of charge separation and transfer, it suggests that $\mathrm{PBTH} /$ gel electrolyte assembly maintained a good charge separation scheme and allowed less charge recombination. It is worth noticing that comparing the potential at which the photocurrent exceeds the dark current (flat-band potential $\mathrm{E}_{\mathrm{fb}}$ ) in Figure $2(\mathrm{~A})$ and Figure $2(\mathrm{~B})$ is $\approx 0.25 \mathrm{~V}$ greater than $\mathrm{E}_{\mathrm{fb}}$ reported for the PBTh in aqueous electrolyte using $\mathrm{Ag} / \mathrm{AgCl}$ reference electrode. Such difference is due to using Platinized FTO in the current study (Figure 1) at both counter and reference electrode.

\subsection{Hole Accumulation Phenomena}

The observed photocurrent spears in Figure 3 can be explained on a basis of the 
existence of hole accumulation in the mixed phases of the organic polymers, as PBTh is considered to be a p-type organic semiconductor. We assume that more than one phase of PBTh is formed, and p-p type heterojunction is created. This allows hole accumulation to take place, as was evident from the appearance of the sharp rise in the photocurrent as shown in Figure 3(A) for As-prepared film, and Figure 3(B) generated 18 months later. The quantitative analysis for the concentration of these hole accumulation and their effect of the transient current time constant showed that the smaller the magnitude of the current spear the longer the transient current time. This can be explained using the following equation [21]:

$$
R=\mathrm{e}^{-\frac{t}{\tau}}
$$

where $t$, time, $\tau$ is a transient time constant and $R=\left(I_{t}-I_{s t}\right) /\left(I_{i n}-I_{s t}\right)$, as $I_{t}$ is current at time $t, I_{\text {in }}$ is immediate photocurrent, and $I_{s t}$ is the stationary value of photocurrent (steady current).

The plot of $\ln R$ vs time generates a straight line with slope $=1 / \tau$. The reciprocal of the slope determines the value of $\tau$, in seconds. The greater $I_{i}$ and the smaller $I_{s t}$ make $R$-value depends on $I_{t}$. In the sharper spear, $I_{t}$ is large, consequently larger $R$, which means larger slope and smaller $\tau$.

Figure 3(B) also shows the reproducibility of the assembly's photocurrent after 18 months elapse. The increase of the photocurrent after the decay of the initial sharp increase is due to the thermal effects on TPGE caused by long-term illumination.

\subsection{Change in the Open Circuit Potential $\mathrm{d}\left(V_{o c}\right)$}

Electron lifetime $\left(\tau_{n}\right)$ contributes to the photoactivity outcome of the studied assemblies. The equation relates $\tau_{n}$ with the open circuit potential ( $\left.V_{o c}\right)$ decay [22]:

$$
\tau_{n}=-\left(k_{B} T / e\right) *\left(\mathrm{~d} V_{o c} / \mathrm{d} t\right)^{-1}
$$

where $k_{B}$ is the Boltzmann constant, $e$ is the electron charge, $T$ is the temperature in $K$, and $V_{o c}$ is the open circuit potential in Volts.

The plot of $V_{o c}$ for As-prepared $\mathrm{PBTh} / \mathrm{I}^{-} / \mathrm{I}_{3}^{-}$gel electrolytes, is displayed in Figure 4. This figure shows a sudden big change in the $V_{o c}$ during dark/illumination transitions. The $\mathrm{d} V_{o d} / \mathrm{d} t$ is $0.22 \mathrm{~V} / \mathrm{s}$ upon transition from illumination to darkness, while $\mathrm{d} V_{o d} / \mathrm{d} t$ is $0.14 \mathrm{~V} / \mathrm{s}$ for the transition from darkness to illumination. These data correspond to $\left(\tau_{n}\right)=115 \mathrm{~ms}$, and $181 \mathrm{~ms}$ respectively. These values are closer to that recorded for PBTh in aqueous electrolytes [23]. The small changes in the $V_{o c}$ under illumination reflect some thermal agitation to the gel electrolyte caused by the light, while that observed under darkness reflects gel relaxation. Similar, but not identical, behavior for the same assembly after 18 months later was observed, where changes in $V_{o c}$ regenerated a similar pattern. The results displayed in Figure 4 may indicate that electron lifetime has two phases due to the thermal effect of illumination on the assembly. 


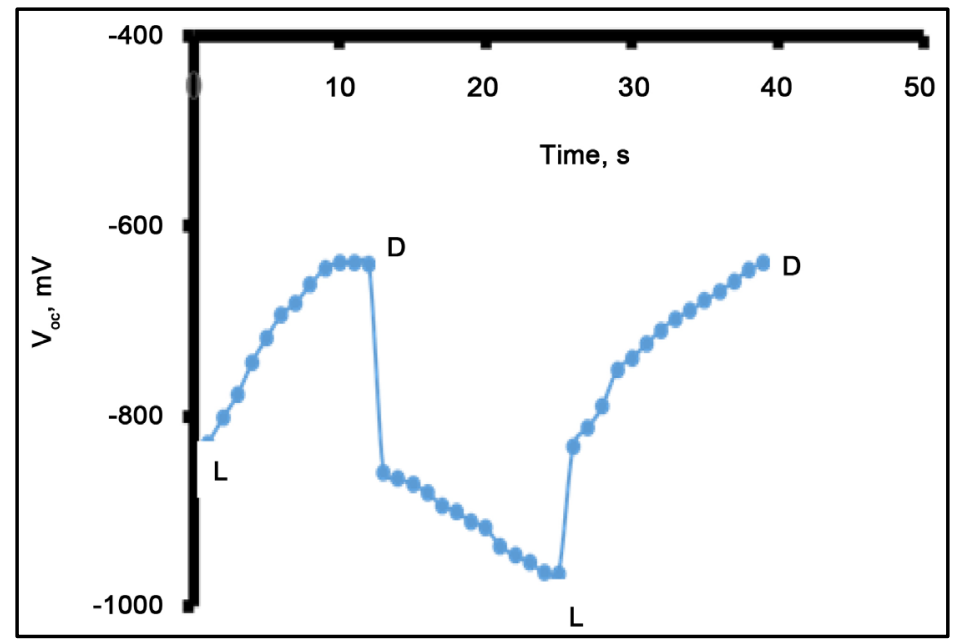

Figure 4. Voc plot for $\mathrm{PBTh} / \mathrm{I}^{-} / \mathrm{I}_{3}^{-}$gel electrolyte recorded for as-prepared PBTh film under Dark (D) and Illumination (L).

\subsection{Electrochemical Behavior of PBTh Occluded with CdS Nanoparticles}

Figure 5(A) displays the CV of PBTh film doped with CdS nanoparticles in $\mathrm{I}^{-} /$ $\mathrm{I}_{3}^{-}$gel electrolyte in the dark and under illumination, while Figure 5(B) displays the $\mathrm{CV}$ for the same assembly 18 months later. These figures clearly show that films of PBTh/CdS sustained their photoactivity as evident with the level of photocurrent generated in a potential range between 0.0 and $-1.0 \mathrm{~V}$. The observed greater photocurrent than dark current indicates that films of $\mathrm{PBTh} / \mathrm{CdS} /$ Gel electrolyte assembly offered a charge separation and small charge recombination. Although this assembly generated less photocurrent after 18 months, the magnitude of the generated photocurrent reflects that the photoactivity was maintained. This is added evidence for the long-time sustainable activity of the gel electrolyte.

Figure 6 shows the photocurrent-time plot at $-1.0 \mathrm{~V}$. As $\mathrm{PBTh} / \mathrm{CdS}$ is a p-type organic semiconductor, the generated assembly show lesser hole accumulation than the PBTh only. The smaller photocurrent spear shown in Figure 6, compared to that displayed in Figure 3, is direct evidence for the effect of CdS nanoparticles on the host polymer PBTh. Figure 6(A) and Figure 6(B) indicate that PBTh/CdS/TPGE assembly maintained its activity for a long period.

\subsection{Electrochemical Impedance Spectroscopy}

Electrochemical impedance spectra of the studied assemblies were measured in a frequency range between $10^{5}-10^{-2} \mathrm{~Hz}$ at $-0.8 \mathrm{~V}$. Impedance complexes (Nyquist plot) generated from the studied $\mathrm{PBTh} / \mathrm{I}^{-} / \mathrm{I}_{3}^{-}$TPGE assembly on FTO substrate in the dark and under illumination, are displayed in Figure 7(A) (as prepared) and Figure 8(A) (18 months later). These Figures indicate that the porosity of the studied films of PBTh is maintained during 18 months of elapsed time. They also show both kinetic and diffusional control characters across the studied 


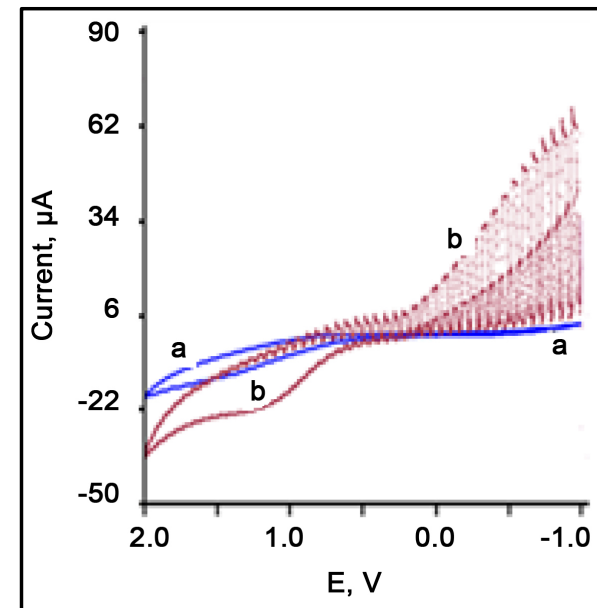

(A)

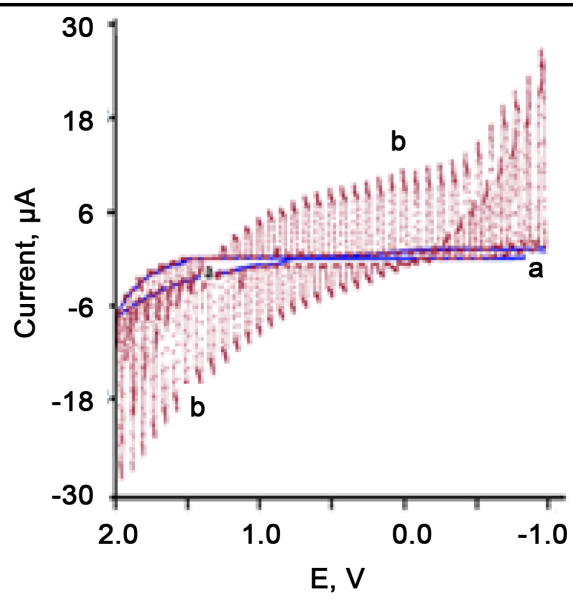

(B)

Figure 5. $\mathrm{CV}$ at scan rate $0.1 \mathrm{~V} / \mathrm{s}$ for $\mathrm{PBTh} / \mathrm{CdS} / \mathrm{I}^{-} / \mathrm{I}_{3}^{-}$gel electrolyte recorded. (A) As-prepared, and (B) 18 months later; (a) dark and (b) under illumination.

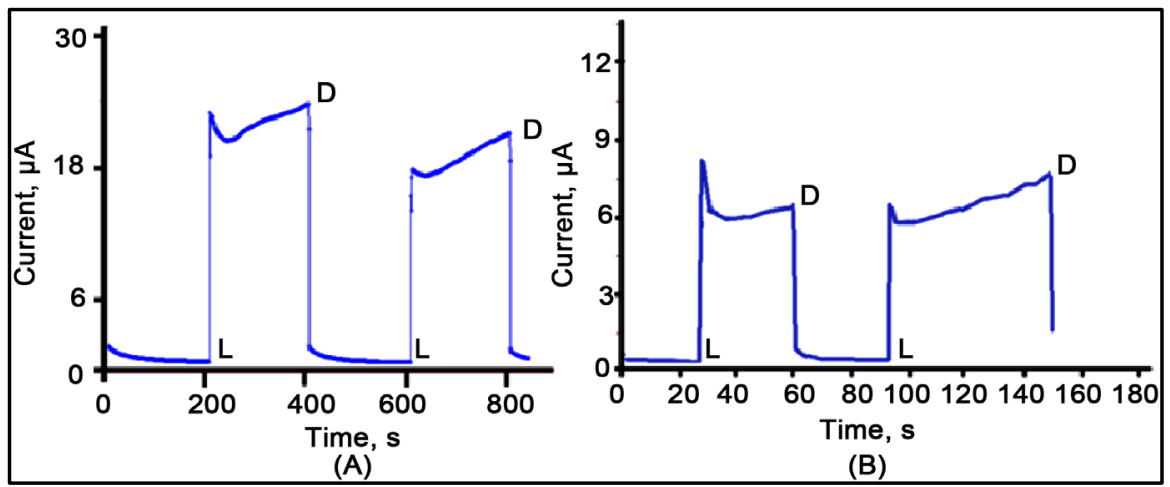

Figure 6. Photocurrent-time at $-1.00 \mathrm{~V}$ plot for $\mathrm{PBTh} / \mathrm{CdS} / \mathrm{I}^{-} / \mathrm{I}_{3}^{-}$gel electrolyte recorded. (A) As-prepared, and (B) 18 months later; D (Dark) and L (under illumination).

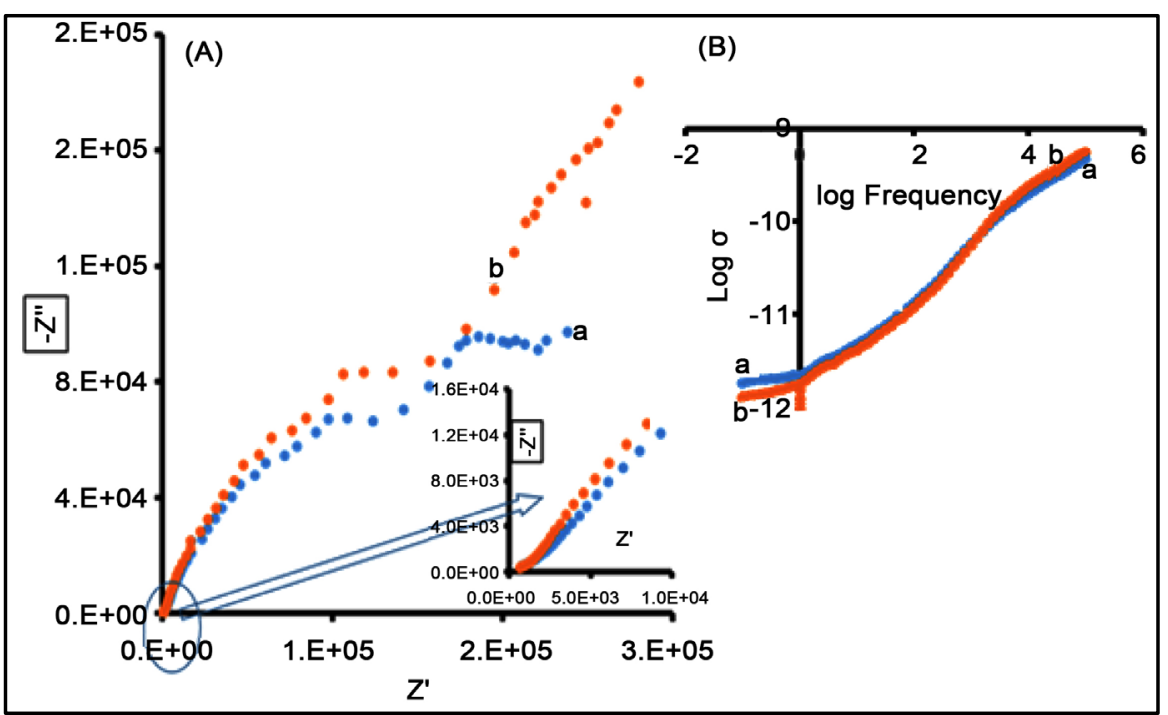

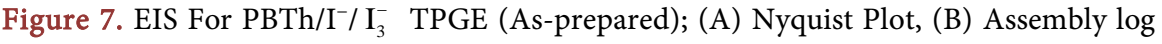
Conductivity $\sigma \mathrm{vs} \log$ frequency; (a) Dark, (b) Illumination. 


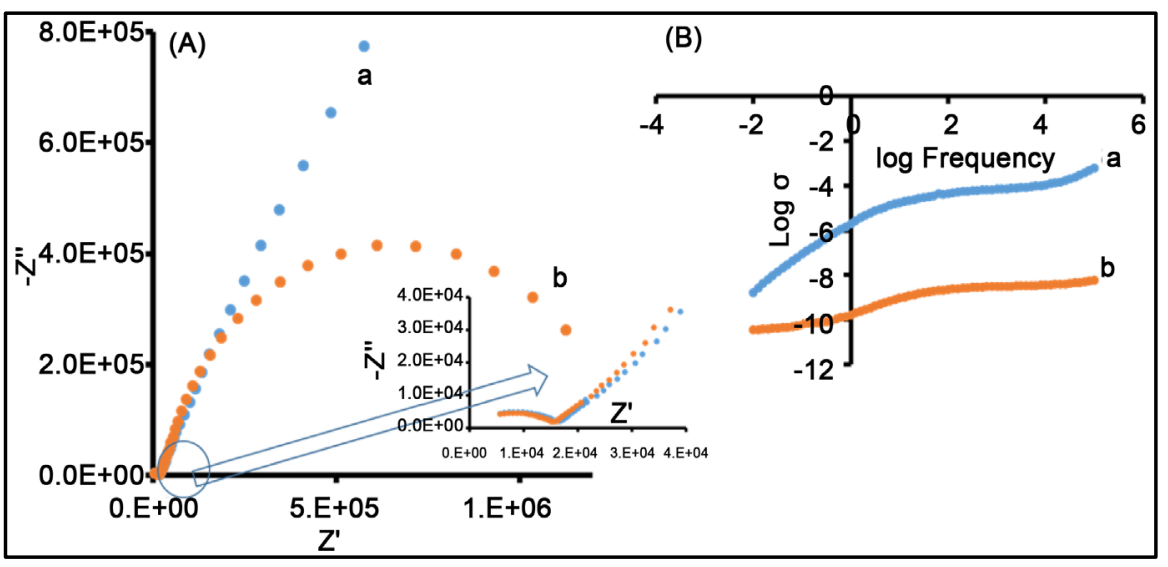

Figure 8. EIS for PBTh/CdS/I / $\mathrm{I}_{3}^{-}$TPGE (18 months later); (A) Nyquist Plot, (B) Assembly $\log$ Conductivity $\sigma$ vs log frequency; (a) Dark, (b) Illumination.

frequency range. This evident from the presence of un-concentered semicircle at high frequencies and the existence of Warburg impedance which reflects the film porosity [24]. Figure 7(B) and Figure 8(B), display the measured AC conductivities $\left(\sigma_{a c}\right)$ as dielectric behavior at $25^{\circ} \mathrm{C}$. AC conductivities $\left(\sigma_{a c}\right)$ were calculated adopting the following equation [25]:

$$
\sigma_{a c}=\frac{L}{a} * \frac{Z^{\prime}}{Z^{\prime 2}+Z^{\prime \prime 2}}
$$

where $L$ is film thickness, and $a$, is the electrode surface area $\left(2.0 \mathrm{~cm}^{2}\right)$.

Figure $7(\mathrm{~B}) \mathrm{b}$ and Figure $8(\mathrm{~B}) \mathrm{b}$ clearly show that under illumination the $\mathrm{AC}$ conductivity increase by increasing the frequency. This increase may be attributed to the decrease of the capacitive reactance of the assembly. This leads to a decrease in the impedance and consequently increases the AC conductivity. The conductivity can also increase due to the hopping of charge carriers at high frequency. The behavior of the assembly, however, was different under dark, where the conductivity of the As-prepared assembly decreased as frequency increased. In Figure $7(B)$ a the plot indicates that as the frequency decreases, the corresponding ac conductivity increases. Such behavior was seen in absence of illumination. Leaving the assembly for 18 months in the dark at room temperature causes certain structural changes in the gel electrolyte. Such changes generated structural conditions that caused decreasing the capacitive reactance as frequency increases. The AC conductivity therefore increases.

\section{Conclusion}

The activities of both the TPGE and the photoactive organic film of poly bithiophene (PBTh) assembled in PEC cells were investigated in 18 months. The reproducible results showed that such assemblies sustained the photoactivity functions and other dielectric properties with infrequent use through an elapsed period of 18 months. The TPGE based Polyethylene glycol/ $\mathrm{I}^{-} / \mathrm{I}_{3}^{-}$is safe, stable with a long life cycle, and can provide a liquid-like electrochemical outcome. 


\section{Acknowledgements}

Indiana University Kokomo supported this research.

\section{Declaration of Competing Interest}

The author asserts that he has no known financial competing interest or personal relationships that could have appeared to dictate the work done in this paper.

\section{References}

[1] Singh, R., Polu, A.R., Bhattacharya, B., Rhee, H.-W., Varlikli, C. and Singh, P.K. (2016) Perspectives for Solid Biopolymer Electrolytes in Dye Sensitized Solar Cell and Battery Application. Renewable and Sustainable Energy Reviews, 65, 1098-1117. https://doi.org/10.1016/j.rser.2016.06.026

[2] MacCallum, J.R. and Vincent, C.A. (1987/1989) Polymer Electrolyte Reviews. Elsevier, London.

[3] Kato, Y., Hori, S., Saito, T., Suzuki, K., Hirayama, M., Mitsui, A., Yonemura, M., Iba, H. and Kanno, R. (2016) High-Power All-Solid-State Batteries Using Sulfide Superionic Conductors. Nature Energy, 1, Article No. 16030. https://doi.org/10.1038/nenergy.2016.30

[4] Xue, Z., He, D. and Xie, X. (2015) Poly(ethylene oxide)-Based Electrolytes for Lithium-Ion Batteries. Journal of Materials Chemistry A, 3, 19218-19253. https://doi.org/10.1039/C5TA03471J

[5] Haque, S.A, Palomares, E., Upadhyaya, H.M., Otley, L., Potter, R.J. and Holmes, A.B. (2003) Flexible Dye Sensitized Nanocrystalline Semiconductor Solar Cells. Chemical Communications, 2003, 3008-3009. https://doi.org/10.1039/b308529e

[6] Zhang, J., Han, H., Wu, S., Xu, S., Yang, Y. and Zhou, C. (2007) Conductive Carbon Nanoparticles Hybrid PEO/P(VDF-HFP)/SiO 2 Nanocomposite Polymer Electrolyte Type Dye Sensitized Solar Cells. Solid State Ionics, 178, 1595-1601. https://doi.org/10.1016/j.ssi.2007.10.009

[7] Hsu, H.-L, Tien, C.-F., Yang, Y.-T. and Leu, J. (2013) Dye-Sensitized Solar Cells Based on Agarose Gel Electrolytes Using Allylimidazolium Iodides and Environmentally Benign Solvents. Electrochimica Acta, 91, 208-213. https://doi.org/10.1016/j.electacta.2012.12.133

[8] Guo, X.Y., Yi, P.F., Wang, W.J., Xiao, S. and Yang, Y. (2013) Effects of Polyethylene Glycol on Agarose Based Magnetic Polymer Electrolyte for Dye-Sensitized Solar Cell. Advanced Materials Research, 860, 652-654. https://doi.org/10.4028/www.scientific.net/AMR.652-654.860

[9] Yang, H., Liu, Z., Chandran, B.K., Deng, J., Yu, J., Qi, D., Li, W., Tang, Y., Zhang, C. and Chen, X. (2015) Self-Protection of Electrochemical Storage Devices via a Thermal Reversible Sol-Gel Transition. Advanced Materials, 27, 5593-5598. https://doi.org/10.1002/adma.201502484

[10] Kelly, J.C., Pepin, M., Huber, D.L., Bunker, B.C. and Roberts, M.E. (2012) Reversible Control of Electrochemical Properties Using Thermally-Responsive Polymer Electrolytes. Advanced Materials, 24, 886-889. https://doi.org/10.1002/adma.201103340

[11] Kelly, J.C., Degrood, N.L. and Roberts, M.E. (2015) Li-Ion Battery Shut-Off at High Temperature Caused by Polymer Phase Separation in Responsive Electrolytes. Chemical Communications, 51, 5448-5451. https://doi.org/10.1039/C4CC10282G 
[12] Kelly, J.C., Gupta, R. and Roberts, M.E. (2015) Responsive Electrolytes That Inhibit Electrochemical Energy Conversion at Elevated Temperatures. Journal of Materials Chemistry A, 3, 4026-4034. https://doi.org/10.1039/C4TA06482H

[13] Daeneke, T., Uemura, Y., Duffy, N.W., Mozer, A.J., Koumura, N., Bach, U. and Spiccia, L. (2012) Aqueous Dye-Sensitized Solar Cell Electrolytes Based on the Ferricyanide-Ferrocyanide Redox Couple. Advanced Materials, 24, 1222-1225. https://doi.org/10.1002/adma.201104837

[14] Vogt, S., Su, Q., Gutiérrez-Sánchez, C. and Nöll, G. (2016) Critical View on Electrochemical Impedance Spectroscopy Using the Ferri/Ferrocyanide Redox Couple at Gold Electrodes. Analytical Chemistry, 88, 4383-4390. https://doi.org/10.1021/acs.analchem.5b04814

[15] Boschloo, G. and Hagfeldt, A. (2009) Characteristics of the Iodide/Triiodide Redox Mediator in Dye-Sensitized Solar Cells. Accounts for Chemical Research, 42, 1819 1826. https://doi.org/10.1021/ar900138m

[16] Pellet, S., Moser, J.-E. and Grätzel, M. (2000) Cooperative Effect of Adsorbed Cations and Iodide on the Interception of Back Electron Transfer in the Dye Sensitization of Nanocrystalline $\mathrm{TiO}_{2}$. The Journal of Physical Chemistry B, 104, 1791-1795. https://doi.org/10.1021/jp9934477

[17] Clifford, J.N., Palomares, E., Nazeeruddin, M.K., Grätzel, M. and Durrant, J.R. (2007) Dye Dependent Regeneration Dynamics in Dye-Sensitized Nanocrystalline Solar Cells: Evidence for the Formation of a Ruthenium Bipyridyl Cation/Iodide Intermediate. The Journal of Physical Chemistry $C, 111,6561-6567$. https://doi.org/10.1021/jp067458t

[18] Orel, B., Šurca Vuk, A., Ješe, R., Lianos, P., Stathatos, E., Judeinsteinc, P. and Colombian, Ph. (2003) Development of Sol-Gel Redox $\mathrm{I}_{3}{ }^{-} / \mathrm{I}^{-}$Electrolytes and Their Application in Hybrid Electrochromic Devices. Solid State Ionics, 165, 235-246. https://doi.org/10.1016/j.ssi.2003.08.037

[19] Wu, J.H., Hao, S.C., Lan, Z., Lin, J.M., Huang, M.L., Huang, Y.F., Fang, L.Q., Yin, S. and Sato, T. (2007) A Thermoplastic Gel Electrolyte for Stable Quasi-Solid-State Dye-Sensitized Solar Cells. Advanced Functional Materials, 17, 2645-2652. https://doi.org/10.1002/adfm.200600621

[20] Kasem, K., Worley, H. and Lovins, A. (2017) Creation of Hybrid Photoactive Inorganic/Organic Interface Assemblies of Cadmium Oxide Mixtures $\left(\mathrm{CdO}_{2} / \mathrm{CdO}\right) /$ Poly-2,2Bithiophene; Optical and Photoelectrochemical Investigations. International Journal of Chemistry, 9, 1-11. https://doi.org/10.5539/ijc.v9n4p71

[21] Spadavecchia, F., Ardizzone, S., Cappelletti, G., Falciola, L., Ceotto, M. and Lotti, D. (2013) Investigation and Optimization of Photocurrent Transient Measurements on Nano- $\mathrm{TiO}_{2}$. Journal of Applied Electrochemistry, 43, 217-225. https://doi.org/10.1007/s10800-012-0485-2

[22] Zaban, A., Greenstien, M. and Bisquert, J. (2003) Determination of the Electron Lifetime in Monocrystalline Dye Solar Cells by Open-Circuit Voltage Decay Measurements. ChemPhysChem, 4, 859-864. https://doi.org/10.1002/cphc.200200615

[23] Kasem, K.K., Worley, H. and Elmasry, M. (2018) Optical and Photoelectrochemical Studies on Photoactive Inorganic/Organic/Organic/Interface Assemblies of CdS/Poly 3-(2-thienyl) aniline/Poly2,2 Bithiophene. Advanced Composites and Hybrid Materials, 1, 748-758. https://doi.org/10.1007/s42114-018-0055-0

[24] Kaiser, H., Beccu, K.D. and Gutjahr, M.A. (1976) Abschätzung der porenstruktur poröser elektroden aus impedanzmessungen. Electrochimica Acta, 21, 539-543. https://doi.org/10.1016/0013-4686(76)85147-X 
[25] Joshia, J.H., Kanchan, D.K., Joshi, M.J., Jethva, H.O. and Parikh, K.D. (2017) Dielectric Relaxation, Complex Impedance, and Modulus Spectroscopic Studies of Mix Phase Rod Like Cobalt Sulfide Nanoparticles. Materials Research Bulletin, 93, 63-73. https://doi.org/10.1016/j.materresbull.2017.04.013 